\title{
Play, Playfulness, Creativity and Innovation
}

\author{
Patrick Bateson $^{1^{*}}$ \\ ${ }^{1}$ Univeristy of Cambridge \\ *Corresponding author (Email: ppgb@cam.ac.uk)
}

Citation - Bateson, P. (2014). Play, playfulness, creativity and innovation. Animal Behavior and Cognition, 1(2), 99-112. doi: 10.12966/abc.05.02.2014

\begin{abstract}
Play, as defined by biologists and psychologists, is probably heterogeneous. On the other hand, playfulness may be a unitary motivational state. Playful play as opposed to activities that merge into aggression is characterized by positive mood, intrinsic motivation, occurring in a protected context and easily disrupted by stress. Playful play is a good measure of positive welfare. It can occupy a substantial part of the waking-life of a young mammal or bird. Numerous functions for play have been proposed and they are by no means mutually exclusive, but some evidence indicates that those individual animals that play most are most likely to survive and reproduce. The link of playful play to creativity and hence to innovation in humans is strong. Considerable evidence suggests that coming up with new ideas requires a different mindset from usefully implementing a new idea.
\end{abstract}

Keywords - Animal play, Human playfulness, Novel solutions, Applying ideas

In the past the study of play has been treated as a non-subject. Since play was regarded as being the opposite of work, it was mistakenly regarded as not being a serious topic for research. In recent years, however, the growth of interest in this form of behavior has exploded. Problems of definition have been greatly eased, partly because the many different uses of 'play' have been identified and excluded from the definition. Playful play as opposed to activities that merge into aggression is characterized by positive mood, intrinsic motivation, occurring in a protected context and easily disrupted by stress. As in scientific research, such play may lead nowhere. Nevertheless, I argue that playful play, in particular, sometimes provides the experience that can generate novel solutions to challenges set by the social and physical environment. I distinguish between such creativity and its implementation in innovative acts. The distinction between creativity and innovation is not often made with animals but is especially clear in humans. Creative people are often not especially innovative and innovative people are often not especially creative, relying on the ideas of others. The arguments in this article are largely condensed version from a book by myself and Paul Martin (Bateson \& Martin, 2013).

\section{Definition}

Play is used in a great number of ways. Brian Sutton-Smith's usage extends from the use of metaphors to beauty contests, playing the piano, playing cricket to doing risky things like bungee jumping (Sutton-Smith, 1997). In contrast most psychologists and biologists use play for non-serious activities that may have no immediate utility. For that reason, rule-governed competitive sports are 'played', but they are rarely if ever conducted playfully. Sports and many games are often treated as being 
deadly serious. Similarly, theatrical plays in which the actors are required to have learned their lines do not have associated with them much lightness of mood, except perhaps in improvisation on the stage and ad libbing.

Over the years a number of psychologists and biologists have attempted to bring order to the subject of play by listing the various criteria by which play behavior might be recognized (Burghardt, 2005; Fagen, 1981). Five defining features of play, which have emerged from studies of play in many species, are:

1. The behavior is spontaneous and rewarding to the individual; it is intrinsically motivated and its performance serves as a goal in itself. Play is 'fun.'

2. The player is to some extent protected from the normal consequences of serious behavior. The behavior appears to have no immediate practical goal or benefit. Social forms of the behavior may be preceded or accompanied by specific signals or facial expressions indicating that the behavior is not serious. Play is the antithesis of 'work' or 'serious' behavior.

3. The behavior consists of actions or, in the case of humans, thoughts, expressed in novel combinations. Social forms of the behavior may be accompanied by temporary changes in social relationships, such as role reversals, in which a normally dominant individual may become temporarily subordinate while playing, and vice versa. Play is a generator of novelty.

4. Individual actions or thoughts are performed repeatedly (though they do not resemble stereotypies such as the circular pacing seen in animals kept in impoverished conditions); they may also be incomplete or exaggerated relative to non-playful behavior in adults. Play looks different.

5. The behavior is sensitive to prevailing conditions and occurs only when the player is free from illness or stress. Play is an indicator of well-being.

These criteria overlap extensively with those articulated by Gordon Burghardt who devoted a substantial portion of his book to characterizing the defining features of play and relating them to observational evidence from numerous species (Burghardt, 2005). His analysis led him to suggest five criteria by which play can be recognized. They are broadly similar to the core features listed above. Neither sets of criteria define playful play. For play to be playful, a sixth feature must also be present:

6. Playful play (as distinct from the broader biological category of play) is accompanied by a particular positive mood state in which the individual is more inclined to behave (and, in the case of humans, think) in a spontaneous and flexible way.

Playfulness, the defining feature of playful play, is a positive mood state that is not always detectable in observable behavior. The behavior of a playful human is captured by numerous synonyms, including cheerful, frisky, frolicsome, good-natured, joyous, merry, rollicking, spirited, sprightly and vivacious. Some of these terms relate to human emotions that could not be readily identified in animals without much anthropomorphic projection. Some, though, are descriptive of visible behavior and can be defined ostensively (i.e., by pointing to the example), such as when two kittens engage vigorously in social play. In animals, as in humans, playfulness may be inferred from the context in which it occurs. What the animals do may vary - from playing with objects at one moment to playing with another individual at the next - but the playful state underlying their behavior is the same.

Play, as defined above, can manifest itself in many different ways in humans. It may be solitary, social, pretend, imaginary, symbolic, verbal, socio-dramatic, constructional, rough-and-tumble, manipulative, and so forth (Pellegrini, 2009; Power, 2000). These different forms of play differ in their 
structure, their underlying motivation and, quite probably, their biological functions. For example, the rough-and-tumble play of a four-year-old child wrestling with another four-year-old is visibly quite different from that of, say, a solitary 10-year-old staring into space, lost in a fantasy. The criteria for recognizing play in animals work well when applied to the rough-and-tumble play of a child, but pretend play requires additional definition (Smith, 2010). Applying non-literal meanings to actions and objects is a central feature of pretend play in humans. It involves imitative actions in a non-functional context, such as pressing a toy stethoscope against the chest of a doll.

Such instances of pretend play are easy to define ostensively by pointing to examples, and a case can be made for defining similar behavior seen in the great apes. For example, young female chimpanzees behave maternally towards sticks, ceasing to do so when they have real offspring to care for (Kahlenberg \& Wrangham, 2010). This stick-carrying behavior consists of holding or cradling sticks, pieces of bark, small logs or woody vines with the hand or mouth, underarm or, most commonly, tucked between the abdomen and thigh. Individuals carry sticks for periods ranging from a minute to more than four hours, during which time they rest, walk, climb, sleep and feed as usual. The occurrence of stick-carrying is greatest among juvenile females and resembles the pretend play of human children.

The pretend play of an older child, who can describe what he or she is thinking and doing, may be viewed as part of a package of characteristically human behavior and cognition, much of which is internalized. This complex package includes the use of language, self-awareness and an understanding of how other humans think and are likely to behave (Smith, 2010). The definition used above would not readily apply to such examples, though many could be described as playful.

The criteria for recognizing play would exclude behavior in which the player is stressed or hurt by another. The unpleasant aspects of human 'play' can include teasing, bullying, shunning, as well as hurting and being hurt. The negative side of 'play' is also apparent in other animals. For example, researchers observed how male adult horses who were most likely to initiate what looked like play were also the ones who, according to other criteria, were the most chronically stressed. The stressed horses behaved as though the 'play' were an outlet for frustrated aggression (Hausberger, Fureix, Bourjade, Wessel-Robert, \& Richard-Yris, 2012). If so, it would not constitute play in the terms defined earlier, and it would certainly not be playful play. Similarly, I have noticed how tense kittens could be just before launching themselves at a sibling. They would arch and swish their tails (Bateson, 2011) If grabbed from behind by a human at just that preparatory phase, they would scream, apparently in fright, and retreat from the other individual. They lacked the positive, relaxed mood associated with playfulness, but if they had not been disturbed their mood would have relaxed and their behavior would have satisfied the core features identified above. Mood can also change in the opposite direction. Occasionally, social play degenerates into a spat and the behavior becomes aggressive. For one of the participating individuals the encounter can become disagreeable and the playful mood rapidly evaporates. The change of mood means that the behavior can no longer be regarded as playful, and if the individual becomes stressed then it may no longer even constitute play.

\section{The extent of playful behavior}

Play behavior has been recognized in a large number of mammal and bird species. As far as the behavior of young mammals is concerned, it seems likely that few if any species will be found where play in one form or another is absent. In birds, play has been recorded in parrots, hornbills, babblers and members of the crow family. The existence or not of play in other vertebrate taxonomic groups is much more controversial (Manning \& Dawkins, 2012). Gordon Burghardt examined the possibility of play in taxonomic groups other than birds and mammals (Burghardt, 2005). He identified instances of behavior in fish and reptiles of behavior that look somewhat like object play in birds and mammals. According to Burghardt, some invertebrates such as octopus and even spiders might also exhibit play-like behavior. For example, sexual acts between males and immature female spiders that do not result in the union of sperm and egg are found to decrease the subsequent latency to an act resulting in fertilization and increase maternal investment in the offspring (Pruitt, Burghardt, \& Riechert, 2012). The authors argued that the 
non-conceptive behavior had formal similarities with play in birds and mammals. The conclusion that spiders and other invertebrates engage in play may seem implausible, even if it does follow logically from a precise definition that works for birds and mammals. What this example does illustrate is the considerable difficulty of defining play.

As in humans, the play of other species can manifest itself in distinctly different forms. For example, when describing play in a mammal as generally playful as the domestic cat, it becomes clear that different components of its play behavior are displayed in different situations. For instance, arching of the back, which is often seen in social play, does not appear in play with objects. Similarly, the pouncing on objects, especially furry objects, is not seen in locomotor play. Moreover, the developmental trajectories of these different forms of play are not the same. In cats, social play starts well before weaning, whereas object play rises sharply in the seventh week after birth, several weeks after the kittens have started to take solid food. Different structural features are therefore required to characterize these different sub-categories of play.

Dolphins are magnificently playful animals and particularly good subjects for investigating the different manifestations of play. Captive dolphins play readily with balls and other toys. In the wild, they play with feathers, seaweed, sponges and other objects. They also play with bubble rings, which they create for themselves from their blowholes. Dolphins play with these items in a variety of ways, such as pushing them around, throwing them in the air or swimming through their bubble rings. They are also highly social, playing extensively with each other. Thirty-seven different types of play have been described in the young of the bottlenose dolphin (Kuczaj, Makecha, Trone, Paulos, \& Ramos, 2006). Examples included holding a ball, swimming and tossing a ball simultaneously, using the mouth or chin to dribble a ball at the surface or under the water, pushing a ball with a body part, trapping a ball between a hard surface and part of the body, using a ball as a rubbing tool, and placing a ball into enclosed spaces and then releasing it. These and other categories of play are spontaneously produced by the dolphins and need no reinforcement by trainers with rewards of food or praise.

In some species, specific social signals are used to denote that what follows is play rather than serious behavior. Dogs, for example, signal their readiness to play by dropping down on their forelegs and wagging their tails. In domestic cats, a bout of social play is often initiated by one kitten crouching with its head held low and paddling its back legs before pouncing on another kitten (West, 1974). Chimpanzees have a special 'play face' - a distinctive facial expression that precedes and accompanies a bout of social play.

Social play is marked by a degree of cooperation between the players. Competition is limited and roles are often reversed. So individuals that are normally dominant in non-playful contexts may allow themselves to adopt a subordinate role during play and vice versa. A mother cat playing with her kitten will sometimes be the object of a playful attack and sometimes initiate it (Mendl, 1988). This exchange of roles during play is particularly striking when members of different species are reared together, such as dogs and cats, cats and rats, dogs and deer, dolphins and whales, and so on. The participants play avidly and they frequently exchange roles, as if they share the same set of basic rules for play.

When social play is in full swing, many patterns of 'serious' behavior are apparent but they are not exactly the same in form or motivation. Playing kittens may pounce on each other, as though fighting or attacking prey, but their biting is soft and when they wrestle their claws are retracted. (This seems to be an inhibition that emerges as the animals get older, because earlier in development they can bite hard and scratch each other.) Similarly, playing monkeys may mount each other, as though sexually, but no actual penetration occurs.

While the occurrence of play tends to decline with the onset of adulthood, it may still be seen in later life. Play is obvious at times in adult domestic cats and dogs. Their behavior is not just a consequence of domestication, because play in adults has also been seen in many wild species including wolves, coyotes, Cape hunting dogs, gorillas and dolphins (Kuczaj et al., 2006). And, of course, play is also seen in adult humans, when they have the time and inclination. Adult humans typically play less than children. 
Another of the defining features of play listed above is its sensitivity to prevailing conditions. In general, play is an indicator of psychological and physical well-being (Held \& Spinka, 2011). It is usually the first activity to disappear if the individual is stressed, anxious, hungry or ill. Experimental evidence backs this up. In one study, for example, playing rats that were exposed to cat hair immediately stopped playing or soliciting play, and their play remained suppressed for several days after this mildly stressful experience (Panksepp, 1998). A number of laboratory and field studies have suggested that young mammals that have been short of food play less compared with when they are better fed; examples include squirrel monkeys. For example, wild-living meerkats were found to play more when they were provisioned with extra food (Sharpe, Clutton-Brock, Brotherton, Cameron, \& Cherry, 2002).

Shortage of food tends to suppress play in humans as well. In a comparison of under-nourished and well-nourished children aged 7-18 months in West Bengal, the under-nourished boys (for whom the sample size was adequate, unlike girls) showed less vigor in their play (Graves, 1976). Similarly, a study of Kenyan toddlers found a correlation between the children's food intake and how much they played (Sigman, Neumann, Baksh, Bwibo, \& McDonald, 1989). Many aspects of poverty, such as a requirement to work, can reduce a child's opportunity for play (Milteer \& Ginsburg, 2012). All are a cause for concern, but reduced motivation to play, caused by poor health and poor nutrition, will compound the other problems. As in other species, children's play happens only when basic short-term needs have been satisfied and the individual is free from stress.

The motivation to play has many of the same characteristics as the motivation for other activities such as eating. The more an individual has been deprived of play, the more it will play when given the opportunity, as though compensating for the previous shortfall (Jensen, 1999). More saliently, an individual is prepared to work in order to be given the opportunity to engage in play. Opportunities to play are themselves rewarding, reinforcing the activity that provided the individual with the chance to play. In one experiment, for example, an opportunity to play worked effectively as a reward when rats made the correct choice in a maze (Humphreys \& Einon, 1981). Like food, the opportunity to play is a natural reinforcer of other behavior.

An individual absorbed in playing seems not to require any external reward. Many experimental psychologists concerned with how behavior is controlled have tended to focus on external rewards or punishments, which are more amenable to experimental manipulation. External rewards such as food are powerful ways of shaping behavior. In the first half of the twentieth century, B.F. Skinner founded a whole school of research in which animals' responses to different schedules of reinforcement with food were automatically recorded. When the reinforcements occur in a particular context, that context can itself become rewarding. So a food reward delivered after the performance of a particular act may be given only when the trainer has, for example, triggered a device that emits a clicking sound. After a while, the sound alone can be used to reward another act. In the language of experimental analysis of behavior, the sound is a secondary reinforcer whereas the food is the primary reinforcer.

Both primary and secondary reinforcers are external and, in the case described, depend on the trained individual being intrinsically motivated to take food. The motivation for learning the rewarded behavior is said to be extrinsic. In the case of play, particularly when the individual is playing on its own, the motivation is intrinsic - that is, no external reward is needed. In social play the reactions of the play partner may provide additional reward, increasing the likelihood that the initiator will continue playing. If the partner does not respond playfully, the initiator will stop. Nevertheless, the initiator's behavior starts spontaneously and may be marked by a characteristic play signal. The spontaneous character of the behavior is obvious and highlights the distinction between extrinsic and intrinsic motivation.

The various forms of play within a species, and the different ways in which these change with age, suggest that different forms of play are controlled differently (Bateson, 1981). Moreover, as play merges with adult behavior, the motivational systems probably change with age. Aggressive acts can become incorporated into social play, and prey-catching in carnivores can become incorporated into object play. 


\section{Function}

What play is for? This question is not directed at the individual's motivation. It is concerned with how the various aspects of play increase the individual's chances of survival and reproducing itself.

In the history of thinking about the function of play a very large number of hypotheses have been offered. When young animals playfully practice the stereotyped movements they will use in earnest later in life, they are often thought to improve the coordination and effectiveness of these behavior patterns. The short dashes and jumps of a young gazelle when it is playing bring benefits that may be almost immediate, as it faces the threat of predation from cheetah or other carnivores intent on a quick meal, and needs considerable skill when escaping (Gomendio, 1988). Even though the benefits may be immediate in such cases, they may also persist into adult life.

Most theories of the functions of play have continued to focus on its role in enabling the developing individual to acquire and practice complex physical skills and, by so doing, fine tune neuromuscular systems. Others, observing how much young animals play with each other, have emphasized that the individual also develops social skills and cements its social relationships; play may also serve to improve its capacity to compete and cooperate with other members of its own species. Play can make an individual more resistant to stress, enlarge its repertoire. Play may enhance an individual's resourcefulness and flexibility and make it able to adjust to new conditions. Play may enhance its ability to cooperate with others and to co-exist with older members of its own species. Play may increase its knowledge of its home range. Play, or at least some components of it, allows the young animal to simulate, in a relatively safe context, potentially dangerous situations that will arise in its adult life. They learn from their mistakes, but do so in relative safety. On this view, play exerts its most important developmental effects on risky adult behavior such as fighting, mating in the face of serious competition, catching dangerous prey and avoiding becoming someone else's prey. Indeed, the behavior patterns of fighting and prey-catching are especially obvious in the play of cats and other predators, whereas safe activities such as grooming, defecating and urinating have no playful counterparts. None of the suggestions about the function of play are mutually exclusive. Moreover, if play is heterogeneous, as I believe it is, then the plethora of explanations is hardly surprising.

When differences between the sexes arise in play, as they often do, these are reflected in differences between the sexes in the activities of adults (Meaney \& Stewart, 1985). For instance young female chimpanzees seem to behave maternally towards sticks, doing so much more than males and ceasing to do so when they have real offspring to care for (Kahlenberg \& Wrangham, 2010). Stickcarrying consisted of holding or cradling detached sticks pieces of bark, small logs or woody vine, with their hand or mouth, underarm or, most commonly, tucked between the abdomen and thigh. Individuals carried sticks for periods of one minute to more than four hours during which they rested, walked, climbed, slept and fed as usual. The occurrence of stick-carrying peaked among juveniles and was higher in females than males. This sex difference could not be explained by a general propensity for females to play with objects more than males, because several types of object such as weapons were played with more by males. Males in many species, including humans do more rough and tumble play than females and engage in more agonistic behavior when adult (Auger \& Olesen, 2009).

The ideas about play leading to the acquisition of knowledge and greater resilience with longterm benefits are distinct from the idea of play as a mechanism for generating novel solutions, which is the primary thrust of this chapter. Play has features that are likely to make it especially suitable for finding the best way forward in a world of conflicting demands. In acquiring cognitive skills, individuals are in danger of finding sub-optimal solutions to the many problems that confront them. In deliberately moving away from what might look like the final resting point, each individual may get somewhere that is better. Play may, therefore, fulfill an important probing role that enables the individual to escape from false end-points or 'local optima'. An analogy is a mountain surrounded by lesser peaks. A climber might get to the top of a lesser peak only to discover that she had to descend before scaling a higher one. When on a metaphorical lower peak, active ways of getting off it can be highly beneficial. In practice what this 
could mean that the activities involved in play discover possibilities that are better than those obtained without play.

\section{Testing the hypotheses about function}

The utility to an individual of having a characteristic that enhances its chances of surviving and reproducing is testable in principle but much less often so in practice. Evidence for the utility of play has not been readily forthcoming (Martin \& Caro, 1985). Nevertheless, play has real biological costs. Animals expend more energy and expose themselves to greater risks of injury and predation when they are playing than when they are resting. Play makes them more conspicuous and less vigilant. For example, young Southern fur seals are much more likely to be killed by sea lions when they are playing in the sea than at other times when they are in the sea (Harcourt, 1991). The costs of play must presumably be outweighed by its benefits, otherwise animals that played would be at a disadvantage compared with those that did not. Among the suggested costs for human children are poor socialization, poor physical fitness, poor mental health and poor creativity. If play is beneficial, then it follows that depriving the young animal of opportunities for play should have harmful effects on the outcome of its development other things being equal.

Play interactions by rats enhanced their subsequent behavioral plasticity and response to novel situations. Rats were reared from 20 to 50 days in one of three conditions: in pairs; or in isolation with or without 1 hour of daily play fighting experience (Einon \& Potegal, 1991). They were rehoused in small groups at 50 days, when the frequency of play starts to wane, so that they were not isolated at the time of testing. They were tested for how they responded defensively at 80 to 100 days by being placed in the home cage of another adult for 10 minutes. Play-deprived animals spent significantly more time immobile after they had been attacked than did animals of the other two groups. The increased immobility associated with play fighting deprivation was not caused by baseline differences in emotionality such as those elicited by a novel environment, the presence of a strange animal, or nonsocial aversive stimuli. Furthermore, play-deprived rats were not more reactive when pinched with forceps to stimulate a bite delivered by a conspecific, whether or not another rat was present behind a divider.

The deprivation experiments suggest that previously isolated rats' greater reactivity is restricted to situations involving pain coupled with close proximity to and contact with another rat. Since no differences in defensive behavior occur, the maladaptive effect of play deprivation would seem to be specific.

A different approach to understanding the functions of play relies on correlations between the behavior of young animals and their subsequent lives. Play and survival in the offspring of 11 families of individually identified, free-ranging brown bears in Alaska (Fagen \& Fagen, 2004). Cubs which played more during their first summer survived better from their first summer to the end of their second summer. This could have been for a variety of reasons. The Fagens examined statistically several potential confounding factors: cub condition, prenatal and first-year salmon availability (an important resource for bears), and maternal characteristics were examined statistically (Fagen \& Fagen, 2009). They controlled for these factors and confirmed that the more the bears had played when they were cubs, the more likely they were to survive to their first year. The association between amount of play and survival persisted into subsequent years of the bear's lives when they reach independence. The amount of play accounted for $35 \%$ of the variance in the percentage that survived. Just how play benefited the bear cubs could not be determined but the pre-adult mortality might result from events occurring during the stressful environmental conditions of winter hibernation and early spring. Resistance to exposure and infectious disease might be involved. Possibly play produces a more resilient individual both behaviorally and immunologically. If so, it would be capable of withstanding stress in ways that physical condition alone would not predict. In other populations or species, these same factors could still be important, but in different ways - in mediating development and performance of behavior patterns involving predator avoidance and defense, for example. Predator avoidance and defense necessarily involve cognition and emotion, whether the argument is made in physiological terms or in behavioral terms. 
In a study of feral horses, maternal condition influenced play behavior only in males, with sons of mothers in good condition playing more (Cameron, Linklater, Stafford, \& Minot, 2008). When a son and a daughter of the same mother were compared, the daughter played more when its mother was in poor condition and sons played more when their mother was in good condition. Mothers of foals that played more lost more condition and weaned their foals earlier indicating that play behavior was affected by maternal investment. An important finding of the study was that those individuals that played more survived better and had better body condition as yearlings despite being weaning earlier.

In both the studies of free-living bears and horses, it remains possible that an unmeasured third variable explained the results. The individuals that played less may have been less healthy from the outset. Nevertheless, the results are consistent with the hypothesis that playing when young reaps benefits later in life.

\section{Creative animals}

In one of Aesop's fables a crow, half-dead with thirst, came upon a pitcher but found very little water in it. He could not reach far enough down with his beak to get at the water. After many attempts he took a pebble and dropped it into the pitcher. He went on dropping in pebbles, raising the water level a little at a time, until at last he was able to reach the water.

The fable has now become a reality, not with a crow but another member of the crow family, the rook (Bird \& Emery, 2009). In the rook's case the prize was a mealworm lying on the surface of water in a transparent plastic tube. The rook could not reach the mealworm with her beak, but just as in Aesop's fable, when given a pile of pebbles, the bird dropped pebbles into the water one by one until she had raised the water level enough and she could reach the larva.

The experiment was extended with two Eurasian Jays, also members of the crow family (Cheke, Bird, \& Clayton, 2011). The birds were given piles of two different types of objects that could be dropped into the water. One was a pile of pebbles and one was a pile of pieces of cork of the same size as the pebbles. The Jays quickly discriminated between the pebbles that raised the water level and the corks that floated on top and did nothing to raise the level.

Many years before, similar examples of apparently immediate and insightful understanding of problems were found in chimpanzees (Köhler, 1925). When a banana was suspended out of reach of the chimps, they piled wooden boxes on top of each other so that the banana was within reach when they climbed on top of the platform they had created for themselves. In another experiment Köhler gave the chimps sticks which could be slotted together and used to reach bananas placed more than arm's length away outside their cage. The chimps seemed to have a clear idea of what to do in each case. In Köhler's phrase they were "unwaveringly purposeful." No trial and error was required. They had insight into the problems that Köhler had set for them. It was as though they said to themselves: "Aha, I know what to do."

Innovatory use of tools has been frequently observed in both birds and mammals. Among the birds members of the crow family and parrot family provide striking examples. In particular, the kea (Huber, Rechberger, \& Taborsky, 2001) and the New Caledonian crow (Hunt, 1996) are especially remarkable. The two species were compared using a box that could be accessed in different ways (Auersperg, von Bayern, Gajdon, Huber, \& Kacelnik, 2011). Food could be extracted by four different techniques, two of them involving tools. If a stick tool was used it had to be manipulated so that a food reward could be knocked off a pole and delivered to a point where the bird could get it. If a marble ball was used as a tool, it had to be inserted into an opening, which connected to a tube directed at the central pole on which was placed a food reward. When inserted into the tube the marble rolled down the tube and knocked the reward off the pole and the food was again delivered to a point where the bird could get it. The crows were more efficient in using the stick tool, the kea the ball tool. The differences reflected in part the ease with which the two species could handle the tools. 
The dolphins and related sea mammals are extraordinarily creative. In captive conditions roughtoothed dolphins were trained to produce novel behaviors on command, and were reinforced for doing so (Pryor, Haag, \& O'Reilly, 1969). This procedure resulted in significant increases in novel behavior, and demonstrated that the dolphins could remember behavior patterns that they had already performed and could learn to produce novel patterns for which they had not previously been. In the wild the generation of bubbles from their blowhole under water was used by a bottlenose dolphin to drive its fish prey to the surface where it could readily catch them (Fertl \& Wilson, 1997).

A remarkable example of innovation is the cooperative foraging in small groups of hump-backed whales observed in Southeast Alaska and the west coast of South America. Many species of marine mammals use bubbles to catch prey, but some hump-backed whales are unique in the elaborate way they use the bubbles to surround shoals of herrings. One whale blows a long, circular line of bubbles that rise to make a curtain. Other whales make calls that drive the herring towards the bubble wall. As the fish come close to the bubbles, the bubble-blowing whale encloses the wall of bubbles around them, creating a cylinder with the fish trapped inside. The other whales position themselves at the bottom of the cylinder and the herring flee upwards driven by the whales' calls from beneath them. The whales move upwards together and as they approach the surface, each one opens its mouth wide and consumes the fish in a big gulp. With its buccal cavity full, the whale closes its mouths and forces all of the water out by straining it through the baleen that hangs down from the palate. This keeps all of the food inside while getting rid of the water. At this point, the whales can swallow their food (Wiley et al., 2011). This remarkable technique only occurs in a few populations of humpback whales, most notably those feeding in southern Alaska, suggesting that at one point it was an innovation.

These examples of innovative solutions to problems suggest remarkable cognitive abilities on the part of the animals. But how did these abilities develop? One possibility is that they are expressed spontaneously, involving little or no dependence on relevant previous experience.

Another possibility often raised in discussions of innovation is that the individual had generalized from experience obtained in other contexts (Shettleworth, 2010). In the course of play earlier in their lives, individuals discovered properties of the environment that proved crucial when they were later faced with a new challenge. Young crows are extremely playful, actively manipulating objects in ways that could reveal much about what leads to what. They certainly pick up small stones and they may even drop them into puddles raising the level of the water. Similarly young chimps readily play with sticks and if they had been given bamboo sticks might have discovered that the smaller one could be threaded inside the hole of the larger one and so created a longer stick. This was supported by one small scale experiment which indicated that a chimp with prior opportunity to play with sticks solved the problem whereas individuals that had not had such an opportunity failed (Birch, 1945). As for the whales, their much better studied relatives, the dolphins, are renowned for their playfulness. Maybe the whales too had put together their remarkable hunting technique from playfully blowing bubbles and learning that fish would not swim through a bubble screen. Then they cooperated to create a cylindrical screen and drive the fish upwards to the surface where they could be caught easily.

\section{What is creativity?}

A broad distinction may be drawn between creativity and innovation (Bateson \& Martin, 2013). In human behavior, creativity refers to coming up with a new idea whereas innovation refers to changing the way things are done. Although creativity and innovation are often treated as synonymous, the terms can be usefully distinguished. Measures of human creativity have been strongly influenced by the distinction between converging and diverging styles of thought (Guilford, 1956). When asked about what can be done with, say, a brick, the converger says it is used for building a wall. The diverger suggests many different uses, such as a doorstop, a hammer, breaking windows, repelling an attacker, grinding up to make red paste, and so forth. The differences are measured by what is called the 'Alternate Uses Task.' 
Torrance identified three main components of creativity: fluency, flexibility and originality (Torrance, 1972). Fluency refers to the number of unique ideas that are generated when a person is asked about uses for a particular object. Flexibility refers to the capacity to switch between approaches; someone who generates ideas within one category will be perceived as less flexible than someone who generates ideas from multiple categories. Originality refers to the novelty of an idea without relying on routine or habitual thought. It is possible for somebody to be fluent without being original or original without being fluent. A fluent person might come up with a long list of commonplace uses for a brick. An original person would suggest uses that none had thought of before.

Creativity is usually necessary for innovation but it is not sufficient. Indeed, the most creative people are often not the best innovators. In the arts and sciences the distinction may be blurred because creativity does not necessarily involve implementation of any kind. The creativity is regarded as innovative because judgment is involved and the outcome affects others. The distinction between creativity and innovation is not nearly so clear in many of the animal examples. Even so, considerable time can elapse between a creative act and a subsequent innovation. In humans some individuals are better at being creative than they are at being innovative and some innovators rely on the ideas of others. In animals, that difference is harder to observe and generally what is seen is the end product of what may be a long process. The exceptions are the novel behavior patterns expressed by dolphins.

\section{Links between playfulness and creativity}

Play in the restrictive sense that I have used it here involves breaking the rules. Playful play involves having fun while doing so. From the play may emerge a new perspective or a tool that might be used at a later date in combination with other tools to solve a new challenge. In their different ways both of these aspects of play are creative.

Bateson \& Martin (2013) give examples of the links to creativity. Wolfgang Amadeus Mozart was well known, notorious even, for his playfulness. The high-spirited pranks and jokes were also reflected in his music. For example his three-voice canon (KV559) consists of a nonsensical Latin text which when sung sounds like bawdy German. Pablo Picasso was once filmed painting onto glass. The onlooker saw the picture emerge, but viewed from the other side of the glass. Picasso started by quickly sketching a goat and then rapidly embellishing it. Other shapes appeared and disappeared; colors were mixed and transformed. By the end of the film the goat had long since gone and it would have been hard to say what the picture was all about. Picasso had been playing - probably showing off - but clearly enjoying himself hugely.

M.C. Escher (1989) wrote about his art in the following way: "I can't keep from fooling around with our irrefutable certainties. It is, for example, a pleasure knowingly to mix up two- and threedimensionalities, flat and spatial, and to make fun of gravity." Famous products of this approach were his impossible staircases.

The discoverer of the anti-bacterial properties of penicillin, Alexander Fleming, was famous for his playfulness. He was accused disapprovingly by his boss of treating research like a game, finding it all great fun. When asked what he did, he said that: "I play with microbes" and went on "... it is very pleasant to break the rules and to be able to find something that nobody had thought of." (Maurois, 1959, p. 211). Another famously playful scientist and Nobel prize-winner was Richard Feynman. When he was getting bored with physics at an early stage in his career, he wrote: "Physics disgusts me a little bit now, but I used to enjoy doing physics. Why did I enjoy it? I used to play with it. I used to do whatever I felt like doing - it didn't have to do with whether it was important for the development of nuclear physics, but whether it was interesting and amusing for me to play with." He decided that he would play with physics again irrespective of how it important it might be. Then while playing at work, everything flowed effortlessly and he made fundamental contributions to nuclear physics.

Social play is marked by the cooperation between the partners. It is non-competitive and roles may be reversed. So individuals that are dominant in non-playful contexts may allow themselves to adopt a sub-ordinate role during play. Sometimes the playfulness is explicit. Jim Watson described the playful 
nature of scientific creativity when he and Francis Crick had set themselves the task of uncovering the structure of DNA (Watson, 1968). Their main working tool had been a set of colored balls superficially resembling the toys of pre-school children. Watson wrote: "All we had to do was to construct a set of molecular models and begin to play - with luck, the structure would be a helix." It was indeed a helix and the paired structure of the helix provided the means for the molecule to replicate itself. Another example of the role of playfulness in cooperative scientific creativity is provided by Andre Geim and Konstantin Novoselov, who won the 2010 Nobel Prize for physics. The prize was awarded for their discovery of the wonder material graphene.

The celebrated examples of playful people who are also enormously creative are striking, but they may be exceptional. Is this link between playfulness and creativity more general? To find out, people were asked in an online survey whether they viewed themselves as playful and creative (Bateson \& Nettle, 2014). The respondents were presented with a series of statements and asked to state whether each one was very characteristic of themselves and, if so, to score 1 or very uncharacteristic of themselves and, if so, to score 7. They could score anywhere between 1 and 7 depending on their sense of how the statement reflected their own behavior. "Acting playfully" and "Coming up with new ideas" were the statements in which we were particularly interested. These statements were embedded in a number of other statements designed to assess different dimensions of personality (Nettle, 2007). 1536 people responded to the survey. The individuals who reckoned that they were playful also reckoned that they were creative. The correlation between "Acting playfully" and "Coming up with new ideas" was massively significant. To validate this finding, the respondents were asked to offer ideas for the uses of two items, a jam jar and a paperclip. Those individuals who produce few answers are referred to as "convergers" and those who produce many suggestions are known as "divergers." The typical response from a converger when asked for uses for a paper clip was "Clip paper together." The response from one diverger (presumably a woman) was: "Clip papers, unfold to clean fingernails, clip bra, general clothes fixing in an emergency, put on a magnet for a science experiment for children, make a mobile with lots of them, make a sculpture with one or more of them, earrings, pick a lock." The respondents who regarded themselves as playful and producers of new ideas were massively more likely give lots of uses for a jam jar and a paper clip.

Human creativity has doubtless many dimensions. The creative gifts of the person with a schizotypal personality (Nettle, 2002), the capacity to develop novel ideas while day-dreaming (Baird, Smallwood, \& Schooler, 2011), the ability to see connections between different images after a glass of wine (Jarosz, Colflesh, \& Wiley, 2012), and the capacity to suggest many different uses for an object are unlikely to represent a unitary cognitive phenomenon (Batey \& Furnham, 2006). The survey suggested that playfulness may also facilitate creativity.

Creativity can be influenced by specific forms of education. Courses to enhance creativity in adults have been established and are sometimes successful. Practical measures can also help. Even so, a number of obstacles lie in the path of personal creativity (Csikszentmihalyi, 1996). Exhaustion from too many demands, distractions that fragment thought, plain laziness, and lack of direction can all get in the way of being creative. He argued that all of these can be overcome and offered advice on how to do it. The first step, he suggested, is to free up time from the pursuit of predictable goals in order to engage curiosity and look for surprises. With mental energy enhanced, Csikszentmihalyi recommended deliberately avoiding time-wasting distractions, such as aimlessly watching television, and making use of the natural rhythms of the body since most people are especially productive at certain times of the day. He also suggested finding particular spaces and places that enhance reflective thought and creativity.

Mood is crucial. Many authors have noted how a positive state of mind stimulates creativity (Lyubomirsky, King, \& Diener, 2005). That positive state can be enhanced by humor. Humor and play have common features. They both involve social signals, are associated with a positive mood and are sensitive to prevailing conditions. They both tend to occur in protected environments, they are intrinsically motivated, and they do not require additional external reward. Certain forms of humor, like play, rely on generating novel combinations of thoughts and the consequences can be highly creative. These links between playfulness and humor may be much more than mere analogies. Playfulness 
encourages humor and humor encourages playfulness and the result is greater creativity. Another way of enhancing creativity, though controversial, is through the use of drugs.

\section{Psycho-active drugs}

Numerous drugs besides alcohol have been used to create altered states of consciousness in many different cultures for thousands of years. Opium from a poppy, cocaine from the leaves of the coca plant, mescalin from the Peyote cactus, ergot from the Claviceps fungi that infect grasses such as rye, psilocybin from two hundred species of Basidiomycota mushrooms, and many more examples all contain a psychoactive substance.

The psychological experience induced in humans under the influence of psychedelic drugs is multifarious and idiosyncratic, but nevertheless a broad range of common characteristics have been identified (Sessa, 2008). These include alterations in the user's perceptions (in all the sensory modalities), changes in the emotions and expansion in an individual's thinking and identity. A particular feature of the experience encompassed by all the above characteristics has special relevance to the creative process. The feature is a general increase in the ability to deal with complexity and an increase in openness, such that the usual restraints that encourage humans to accept pre-conceived ideas about themselves and the world around them are challenged. Another important feature is the tendency for users to assign unique and novel meanings to their experience. When drugs do have some effect, they vary enormously in how they act on the brain.

In the extensive research carried out on psychoactive drugs the emphasis has been on experiences that enable people to perceive things in a different way or connect previously unrelated bits of information. Here the link with play is analogous. Altered states of consciousness induced by some psychoactive drugs occur in protected contexts, for example. More importantly, when people are in such states they combine thoughts in novel combinations.

\section{Conclusions}

The word 'play' is used in many ways that have nothing to do with the activities in animals and human children described by biologists and psychologists. Playful behavior in the sense I have used it in this article is defined by pointing to examples that people readily recognize once they have been shown them. It may involve novel combinations of actions. Some actions occur outside their usual context and may be exaggerated. In the social play of animals, roles may be reversed with the dominant individual handicapping itself. A core feature of play is its intrinsic motivation which is powerful while it lasts. No additional external reward is required. Playful play is associated with a positive mood and when it occurs is taken as an indicator of well-being. The mood is typically suppressed by illness, anxiety or chronic stress and is highly sensitive to prevailing conditions. Playful play may have many functions but I suggest one important role is linked to uncovering new solutions to challenges set by the environment. The benefits may occur long after the necessary experience has been gathered in the course of play.

Many creative people are extremely playful. Those who describe themselves as acting playfully also reckon that they come up with new ideas. Their views of themselves are supported by objective measures of their creativity. I argue that their creativity does not necessarily mean that they are good at implementing their ideas in ways that are useful. Being innovative requires a different way of thinking from coming up with new ideas. Many of the issues that I have raised in this article are ripe for future research. Play, often regarded as a Cinderella subject, has come at last to the ball.

\section{References}

Auersperg, A. M. I., von Bayern, A. M. P., Gajdon, G. K., Huber, L., \& Kacelnik, A. (2011). Flexibility in problem solving and tool use of kea and New Caledonian crows in a multi access box paradigm. PLoS One, 6, e20231. 
Auger, A. P., \& Olesen, K. M. (2009). Brain sex differences and the organisation of juvenile social play behaviour. Journal of Neuroendocrinology, 21, 519-525.

Baird, B., Smallwood, J., \& Schooler, J. W. (2011). Back to the future: Autobiographical planning and the functionality of mind-wandering. Consciousness \& Cognition, 20, 1604-1611.

Bateson, P. (1981). Discontinuities in development and changes in the organization of play in cats. In K. Immelmann, G. W. Barlow, L. Petrinovich, \& M. Main (Eds.), Behavioral development (pp. 281-295). Cambridge, UK: Cambridge University Press.

Bateson, P. (2011). Theories of play. In A. D. Pellegrini (Ed.), The Oxford handbook of the development of play (pp. 41-47). New York, NY: Oxford University Press.

Bateson, P., \& Martin, P. (2013). Play, playfulness, creativity and innovation. Cambridge, UK: Cambridge University Press.

Bateson, P., \& Nettle, D. (2014). Playfulness, ideas and creativity: A survey. Creativity Research Journal, 26.

Batey, M., \& Furnham, A. (2006). Creativity, intelligence, and personality: A critical review of the scattered literature. Genetic, Social, and General Psychology Monographs, 132, 355-429.

Birch, H. G. (1945). The relation of previous experience to insightful problem-solving. Journal of Comparative Psychology, 38, 367-383.

Bird, C. D., \& Emery, N. J. (2009). Rooks use stones to raise the water level to reach a floating worm. Current Biology, 19, 1410-1414.

Burghardt, G. M. (2005). The genesis of animal play: Testing the limits. Cambridge, MA: MIT Press.

Cameron, E. Z., Linklater, W. L., Stafford, K. J., \& Minot, E. O. (2008). Maternal investment results in better foal condition through increased play behaviour in horsess. Animal Behaviour, 76, 1511-1518.

Cheke, L. D., Bird, C. D., \& Clayton, N. S. (2011). Tool-use and instrumental learning in the Eurasian jay (Garrulus glandarius). Animal Cognition, 14, 441-455.

Csikszentmihalyi, M. (1996). Creativity: Flow and the psychology of discovery and invention. New York, NY: Harper Collins.

Einon, D., \& Potegal, M. (1991). Enhanced defense in adult-rats deprived of playfighting experience as juveniles. Aggressive Behavior, 17, 27-40.

Escher, M. C. (1989). Escher on Escher: Exploring the infinite. New York, NY: Abrams.

Fagen, R. (1981). Animal play behavior. New York, NY: Oxford University Press.

Fagen, R., \& Fagen, J. (2004). Juvenile survival and benefits of play behaviour in brown bears, Ursus arctos. Evolutionary Ecology Research, 6, 89-102.

Fagen, R., \& Fagen, J. (2009). Play behaviour and multi-year juvenile survival in free-ranging brown bears, Ursus arctos. Evolutionary Ecology Research, 11, 1-15.

Fertl, D., \& Wilson, B. (1997). Bubble use during prey capture by a lone bottlenose dolphin (Tursiops truncatus). Aquatic Mammals, 23, 113-114.

Gomendio, M. (1988). The development of different types of play in gazelles: Implications for the nature and functions of play. Animal Behaviour, 36, 825-836.

Graves, P. L. (1976). Nutrition, infant behavior, and maternal characteristics: a pilot study in West Bengal, India. American Journal of Clinical Nutrition, 29, 305-319.

Guilford, J. P. (1956). Structure of intellect. Psychological Bulletin, 53, 267-293.

Harcourt, R. (1991). Survivorship costs of play in the South American fur seal. Animal Behaviour, 42, $509-511$.

Hausberger, M., Fureix, C., Bourjade, M., Wessel-Robert, S., \& Richard-Yris, M.-A. (2012). On the significance of adult play: What does social play tell us about adult horse welfare? Naturwissenschaften, 99, 291-302.

Held, S. D. E., \& Spinka, M. (2011). Animal play and animal welfare. Animal Behaviour, 81, 891-899.

Huber, L., Rechberger, S., \& Taborsky, M. (2001). Social learning affects object exploration and manipulation in keas, Nestor notabilis. Animal Behaviour, 62, 945-954.

Humphreys, A. P., \& Einon, D. F. (1981). Play as a reinforcer for maze-learning in juvenile rats. Animal Behaviour, 29, 259-270.

Hunt, G. R. (1996). Manufacture and use of hook-tools by New Caledonian crows. Nature 379, $249-251$.

Jarosz, A. F., Colflesh, G. J. H., \& Wiley, J. (2012). Uncorking the muse: Alcohol intoxication facilitates creative problem solving. Consciousness and Cognition, 31, 487-493.

Jensen, M. B. (1999). Effects of confinement on rebounds of locomotor behaviour of calves and heifers, and the spatial preferences of calves. Applied Animal Behaviour Science, 62, 43-56.

Kahlenberg, S. M., \& Wrangham, R. W. (2010). Sex differences in chimpanzees' use of sticks as play objects resemble those of children. Current Biology, 20, R1067-R1068.

Köhler, W. (1925). The mentality of apes. London, UK: Paul, Trench, \& Trubner. 
Kuczaj, S. A., Makecha, R., Trone, M., Paulos, R. D., \& Ramos, J. A. A. (2006). Role of peers in cultural innovation and cultural transmission: Evidence from the play of dolphin calves. International Journal of Comparative Psychology, 19, 223-240.

Lyubomirsky, S., King, L., \& Diener, E. (2005). The benefits of frequent positive affect: Does happiness lead to success? Psychological Bulletin, 131, 803-855.

Manning, A., \& Dawkins, M. S. (2012). An introduction to animal behaviour, 6th edition. Cambridge, UK: Cambridge University Press.

Martin, P., \& Caro, T. M. (1985). On the functions of play and its role in behavioral development. Advances in the Study of Behavior, 15, 59-103.

Maurois, A. (1959). The life of Alexander Fleming, discoverer of penicillin. London, UK: Jonathan Cape.

Meaney, M. J., \& Stewart, J. (1985). Sex differences in social play: The socialization of sex roles. Advances in the Study of Behavior, 15, 1-58.

Mendl, M. (1988). The effects of litter-size variation on the development of play-behaviour in the domestic cat litters of one and two. Animal Behaviour, 36, 20-34.

Milteer, R. M., \& Ginsburg, K. R. (2012). The importance of play in promoting healthy child development and maintaining strong parent-child bond: Focus on children in poverty. Pediatrics, 129, e204-e213.

Nettle, D. (2002). Strong imagination: Madness, creativity, and human nature. Oxford, UK: Oxford University Press.

Nettle, D. (2007). Personality: What makes you the way you are. Oxford, UK: Oxford University Press.

Panksepp, J. (1998). Affective neuroscience. New York, NY: Oxford University Press.

Pellegrini, A. D. (2009). The role of play in human development. Oxford, UK: Oxford University Press.

Power, T. G. (2000). Play and exploration in children and animals. Mahwah, NJ: Erlbaum.

Pruitt, J. N., Burghardt, G. M., \& Riechert, S. E. (2012). Non-conceptive sexual behavior in spiders: A form of play associated with body condition, personality type, and male intrasexual selection. Ethology, 118, 33-40.

Pryor, K. W., Haag, R., \& O'Reilly, J. (1969). The creative porpoise: Training for novel behavior. Journal of the Experimental Analysis of Behavior, 12, 653-881.

Sessa, B. (2008). Is it time to revisit the role of psychedelic drugs in enhancing human creativity? Journal of Psychopharmacology, 22, 821-827.

Sharpe, L. L., Clutton-Brock, T. H., Brotherton, P. N. M., Cameron, E. Z., \& Cherry, M. I. (2002). Experimental provisioning increases play in free-ranging meerkats. Animal Behaviour, 64, 113-121.

Shettleworth, S. J. (2010). Cognition, evolution and behavior, 2nd edition. New York, NY: Oxford University Press.

Sigman, M., Neumann, C., Baksh, M., Bwibo, N., \& McDonald, M. A. (1989). Relationship between nutrition and development in Kenyan toddlers. Journal of Pediatrics, 115, 357-364.

Smith, P. K. (2010). Children and play. Chichester, UK: Wiley-Blackwell.

Sutton-Smith, B. (1997). The ambiguity of play. Cambridge, MA: Harvard University Press.

Torrance, E. P. (1972). Predictive validity of Torrance tests of creative thinking. Journal of Creative Behavior, 6, 236-252ß.

Watson, J. (1968). The double helix: A personal account of the discovery of the structure of DNA. New York, NY: Scribner.

West, M. (1974). Social play in the cat. American Zoologist, 14, 427-436.

Wiley, D., Ware, C., Bocconcelli, A., Cholewiak, D., Friedlaender, A., Thompson, M., \& Weinrich, M. (2011). Underwater components of humpback whale bubble-net feeding behaviour. Behaviour, 148, 575-602. 